\title{
Evaluation of Three Brief Screening Tests for Older Patients with Mild HIV- Associated Neurocognitive Disorders in the cART Era
}

\author{
Matteo Vassallo ${ }^{1 *}$, Laurence Barbaud ${ }^{1}$, Roxane Fabre ${ }^{2}$, Signe Andersen ${ }^{1}$, Christine Lebrun-Frenay $^{3}$, Heloise Joly ${ }^{3}$, Brigitte Dunais $^{2}$, Nathalie Montagne $^{1}$ and \\ Christian Pradier ${ }^{2}$ \\ ${ }^{1}$ Department of Internal Medicine, Cannes General Hospital, France \\ ${ }^{2}$ Department of Public Health, L'Archet Hospital, University of Nice, France \\ ${ }^{3}$ Department of Neurology, Pasteur Hospital, University of Nice, France
}

"Corresponding author: Matteo Vassallo, Department of Internal Medicine/Infectious Diseases, Cannes General Hospital, France, Tel: 0033493697211; Fax: 0033492183764; E-mail: m.vassallo@ch-cannes.fr

Received date: December 27, 2016; Accepted date: April 06, 2017; Published date: April 13, 2017

Copyright: ( 2017 Vassallo M, et al. This is an open-access article distributed under the terms of the Creative Commons Attribution License, which permits unrestricted use, distribution, and reproduction in any medium, provided the original author and source are credited.

\section{Abstract}

Introduction: Prevalence of HIV-associated neurocognitive disorders (HAND) in the era of antiretrovirals is still high, the majority of clinical phenotypes being represented by mild forms of impairment. Therefore, adequate screening strategies are needed.
\end{abstract}

We compared performance of three brief screening tools for detecting mild forms of HAND in an elderly population.

Methods: Randomly selected patient over 50 years performed a complete neuropsychological evaluation, considered as the gold standard and three brief screening tools: International HIV Dementia Scale (IHDS), Montreal cognitive assessment (MOCA) and a French battery named FIMF and composed by: Frontal ability battery, Isaac set test, Memory span test and Five words test. Sensitivity, specificity, positive predictive value (PPV) and negative predictive value (NPV) of screening tools and possible combinations were analyzed.

Results: 49 patients were tested (mean age 57, 78\% men, nadir CD4 252, CD4 cell count at inclusion 616, 86\% with viral load below 50 copies/ml, 18\% HCV co-infected, 18\% previous illicit drug use, 16\% with AIDS). HAND was diagnosed in 30/49 patients (90\% asymptomatic neurocognitive disorder, $10 \%$ mild neurocognitive disorder).

In detecting HAND, the FIMF battery showed the best performances (sensitivity $87 \%$, specificity $47 \%$, PPV $72 \%$, NPV 69\%). Combination of MOCA, Isaac set test and Memory span test showed sensitivity $90 \%$, specificity $47 \%$, PPV $73 \%$, NPV $75 \%$, with a combined cut-off value of 78 for discriminating HAND.

Conclusion: The combination of MOCA, Isaac set test and Memory span test showed better performances than the majority of screening tools available for detecting mild forms of HAND and should therefore be considered as a useful option for identifying patients requiring neuropsychological evaluation.

Keywords: HIV-associated neurocognitive disorders; Screening tools; cART era

\section{Introduction}

In the era of combination antiretroviral therapies (cART), prevalence of HIV-associated neurocognitive disorders (HAND) is still high, especially in patients over 50 years old, probably as a consequence of age-related cognitive decline and the increasing number of comorbid conditions [1-6]. Indeed, Valcour et al. showed that patients older than 50 years have three-fold higher risks for HIVassociated dementia than younger subjects [3].

The clinical phenotype of neurocognitive disorders in the cART era is generally represented by asymptomatic neurocognitive impairment (ANI) and mild neurocognitive impairment (MND) (90\% of HAND diagnosis), while cases of HIV-associated dementia are very rare $[7,8]$.

J Neurol Neurophysiol, an open access journal
These less severe forms of HAND, however, are associated with loss of quality of life, poorer treatment compliance and in general higher mortality $[9,10]$. Therefore, one of major challenges in the cART era is to diagnose these forms of impairment in order to prevent such complications.

While the gold standard for assessing diagnosis of HAND is a detailed battery of neuropsychological tests [11], which lasts approximately $1 \mathrm{~h}$ and half, the availability of neuropsychologists is scarce in some hospital settings. Therefore, several easy-to-perform screening tools have been developed for identifying patients needing more detailed evaluation [12-15], but their performance for detecting mild forms of HAND has been variable.

In particular, a number of screening tools have been specifically introduced for patients with HIV-associated dementia (HAD), such as the HIV Dementia scale and the International HIV Dementia scale (IHDS) $[16,17]$. Other tools, such as the Mini mental state examination (MMSE) and the Montreal cognitive assessment (MOCA) have been 
Citation: Vassallo M, Barbaud L, Fabre R, Andersen S, Lebrun-Frenay C, et al. (2017) Evaluation of Three Brief Screening Tests for Older Patients with Mild HIV-Associated Neurocognitive Disorders in the CART Era. J Neurol Neurophysiol 8: 421. doi: $10.4172 / 2155-9562.1000421$

Page 2 of 8

used for the HIV population, often with scarce performance in nondemented patients [18-21].

Therefore, more performing tools for detecting patients at risks for mild forms of HAND are needed. A novel screener, named Cognitive Assessment Tool-rapid version (CAT-rapid), combined with IHDS, showed excellent sensitivity and specificity for patients with HAD, while it failed to identify patients with mild HAND [22].

We conducted a prospective study using three different screening tools in a population of HIV-infected patients older than 50 years, where prevalence of HAND is particularly high and the phenotype of impairment is mainly represented by ANI and MND.

\section{Methods}

\section{Participant's selection}

We randomly selected HIV-1-infected patients above 50 years of age among patients followed in the Department of Internal Medicine at Cannes General Hospital. No limits were set concerning CD4+ cell count or HIV viral load.

Exclusion criteria included active opportunistic infection, a change in psychotropic therapy within the past 3 weeks or any neurological history. Patients were asked to provide informed consent. The study was approved by the Ethics Committee.

\section{Neuropsychological evaluation}

Each patient performed a wide range of neuropsychological (NP) tests administered by a single trained neuropsychologist.

According to the American Academy of Neurology (AAN) 2007 revised criteria [11], tests explored a wide spectrum of cognitive domains: learning and recall episodic memory, attention/ concentration, working memory, executive functions, language, visual agnosia and motor/psychomotor speed. Duration of NP evaluation was $2 \mathrm{~h}$.

\section{The following tests were used:}

- Mini Mental State Evaluation (MMSE) for evaluation of global cognitive function [23]

- Grober and Buschke test (also called RL/ RI 16 according to French guidelines) for episodic memory (learning and recall) [24]

- Stroop test for attention/concentration and speed of information processing [25] [26]

- Verbal Fluency for executive functions and lexical access ability

- « Protocole Montreal-Toulouse d'Evaluation des Gnosies Visuelles » for visual agnosia [27]

- Digit Span and Letter-Number-Sequencing for attention/ concentration and working memory [28]

- Grooved Pegboard for motor and psychomotor speed abilities [29]

- Matrix Reasoning and The Trail Making Test for executive functioning [30]

- « Test de Denomination Orale d'Image » for language [31]

- The Mahieux Brief Screening Scale for praxic abilities [32]
The NP scores from each test were transformed into $\mathrm{z}$-scores as described elsewhere [33] and were adjusted for age, gender and years of education, using standardised norms.

Patients were also assessed according to the Montgomery and Asberg Depression Rating Scale (MADRS) to elicit potential behavioural disorders. Moreover, in order to evaluate the potential interference of HAND on daily functioning, patients also performed the Instrumental Activity of Daily Living short version battery, the Mac Nair and Khan questionnaire of cognitive complaints, the Multiple sclerosis Neurological questionnaire and the Perceived Deficits questionnaire.

According to the AAN revised criteria [11], patients with HAND at NP testing were subdivided into 3 categories:

ANI, involving at least two cognitive domains and documented by a performance of at least $1 \mathrm{SD}$ below the mean on NP tests, without interference in everyday functioning. The asymptomatic characteristics of impairment were defined by the Instrumental Activity of Daily Living short version battery and by interviewing the patient and his/her family.

MND, involving at least two cognitive domains and documented by a performance of at least $1 \mathrm{SD}$ below the mean on NP tests, with mild interference in daily functioning.

$\mathrm{HAD}$, involving at least two cognitive domains and documented by a performance of 2 SD below the normative mean on NP tests, with marked interference in daily functioning

Thus, each patient performing $1 \mathrm{SD}$ or more below the mean in at least two cognitive domains was considered as presenting with HAND and classified as ANI or MND, according to interference with daily living, while those performing $2 \mathrm{SD}$ or more in at least two cognitive domains were classified as HAD.

\section{Screening Tools}

In addition to this large battery of neuropsychological tests, which was considered as the gold standard, we proposed to each patient three screening tools, within 3 months from the date of the large battery. The order among the three screening tools was systematically changed, in order to avoid potential bias linked to patient's learning.

The three screening tools used in this study were:

IHDS: it includes measures of psychomotor speed and processing, as well as short-term memory. It scores a maximum of 12 points and in case of performances below 11 patient requires further evaluations [16]

MOCA: it measures attention/concentration, language, episodic memory and executive function, while it does not measure psychomotor speed or speed of information processing. It scores a maximum of 30 points and results below 26 are considered as pathological. In case of education level below high school, 1 point is added to the final score [34]

A local battery, suggested by French national guidelines for the management of HAND [35] and named FIMF as abbreviation of 4 sub-tests initials included:

The frontal ability battery (FAB): It allows a rapid evaluation of executive functions. FAB has the validity for discriminating between fronto-temporal type dementia and Alzheimer disease in mildly demented patients (MMSE>24). It includes the following items: 
Citation: Vassallo M, Barbaud L, Fabre R, Andersen S, Lebrun-Frenay C, et al. (2017) Evaluation of Three Brief Screening Tests for Older Patients with Mild HIV-Associated Neurocognitive Disorders in the CART Era. J Neurol Neurophysiol 8: 421. doi: $10.4172 / 2155-9562.1000421$

Page 3 of 8

similarities, lexical fluency, motor series "Luria" test, conflicting instructions, inhibitory control and prehension behaviour. Each item has a maximum score of 3 . A total cut-off score of 16 is considered as pathological for patients with high school education level or higher, while the cut-off is 15 for those with lower education level [36].

Isaac set test: It is a test on verbal fluency, where patients are asked to cite the highest number of words they can in 4 semantics categories (colours, animals, fruits and cities). For each category, performances are measured on 15 seconds and the operator stops when 10 words are cited or patient has no more word to cite. A global cut-off below 38 is considered as pathological [37].

Memory span test: Commonly used in the Weschler Adult intelligence Scale (WAIS), it measures skills in working memory. The operator presents an increasing series of numbers and patient has to repeat them few moments later and, in a second phase, reversing their order. Subjects not able to correctly reproduce a series of minimum 5 numbers are considered as pathological and need further evaluations [38].

The five words test (FWT): It is a simple and rapid item initially introduced for testing patients with Alzheimer disease. It consists in showing a list of five words to the patient (usually Museum, Lemonade, Grasshopper, Colander and Truck). In accordance with Grober and Buschke neuropsychological concept, it allows assessment of verbal episodic memory [39]. The main steps of the FWT consist of: inducing specific semantic processing, controlling encoding in order to avoid attention deficits and measuring free and cued recall. Cued recall helps to distinguish recall impairment from storage impairment which is evocative of Alzheimer disease. The maximum score is 10 and each performance below this cut-off is considered as pathological [40]

\section{Statistical Analysis}

Associations between NP testing results (Group without HAND vs Group with HAND) and potential risk factors were studied in univariate analyses using the $\chi^{2}$ test for categorical variables and Mann-Whitney test for continuous ones. P-values below 0.05 were considered statistically significant. Statistical analyses were performed using SPSS software.

According to correspondent cut-off values, we then coded each test of the screening tools as normal or impaired. Considering the NP large battery as the gold standard, sensitivity, specificity, positive predictive value (PPV) and negative predictive value (NPV) were measured for the screening tools (IHDS, MOCA and FIMF). Concerning the FIMF battery, we firstly measured performances of each sub-test, than the entire battery, considering as impaired subjects with at least one of four sub-tests below the norms.

Once most performing tests were identified, we then tried to look at combinations of tests from different screening tools in order to define the best set.

In addition to this analysis where screening tools were considered as a qualitative variable (normal or impaired), we analysed performances in the combination of tests as a quantitative variable, according to scores for each test, in order to identify a global cut-off value which could be discriminant for HAND. A receiver operating characteristic (ROC) curve was then created for this analysis.

\section{Results}

\section{Characteristics of patients}

From September 2012 to October 2013, 49 subjects have been randomly included (mean age 57, 78\% men, nadir CD4 252, CD4 cell count at inclusion $616,86 \%$ with viral load below 50 copies $/ \mathrm{ml}, 18 \%$ HCV co-infected, $18 \%$ previous IDU, $16 \%$ with AIDS. Among comorbid conditions, 36\% had hypertension, 33\% dyslipidemia, 33\% smoking and $18 \%$ HCV co-infection, Table 1).

\section{NP testing results}

According to the NP large battery, 30 out of 49 patients had HAND (61\%), with the large majority represented by ANI ( 27 out of $30,90 \%)$, while 3 had MND (10\%) and anyone HAD.

Main impairments found were executive functions (20 out of 30 patients, $67 \%)$, working memory $(19 / 30,63 \%)$, motor speed $(13 / 30$, $43 \%)$, speed of information processing $(12 / 30,40 \%)$ and learning memory $(12 / 30,40 \%)$. No patients were suffering from severe depression.

Characteristics of patients did not differ between the HAND and no HAND group, apart from more smokers among impaired subjects (Table 1).

\begin{tabular}{|c|c|c|c|c|}
\hline & Total population & Patients without HAND & Patients with HAND & \\
\hline & n (\%) or mean (SD) & n (\%) or mean (SD) & n (\%) or mean (SD) & \\
\hline Number of patients & 49 & 19 & 30 & \\
\hline Male & $38(78)$ & $13(68)$ & $25(83)$ & 0.23 \\
\hline Age (years) & $56,8(4,6)$ & $57(4,8)$ & $57(4,6$ & 0.99 \\
\hline Education level below high school & $34(69)$ & $12(63)$ & $22(73)$ & 0.45 \\
\hline Previous IDU & $9(18)$ & $3(16)$ & $6(20)$ & 0.71 \\
\hline Duration of HIV infection (years) & $17,6(8,3)$ & $17(9)$ & $17,9(7,9)$ & 0.7 \\
\hline Previous AIDS event & $8(16)$ & $3(16)$ & $5(17)$ & 0.93 \\
\hline Hepatitis C co-infection & $9(18)$ & $2(11)$ & $7(23)$ & 0.24 \\
\hline
\end{tabular}


Citation: Vassallo M, Barbaud L, Fabre R, Andersen S, Lebrun-Frenay C, et al. (2017) Evaluation of Three Brief Screening Tests for Older Patients with Mild HIV-Associated Neurocognitive Disorders in the CART Era. J Neurol Neurophysiol 8: 421. doi: $10.4172 / 2155-9562.1000421$

\begin{tabular}{|c|c|c|c|c|}
\hline Hypertension & $17(35)$ & $6(32)$ & $11(37)$ & 0.71 \\
\hline Dyslipidemia & $16(33)$ & $8(42)$ & $8(27)$ & 0.26 \\
\hline Smoking & $16(33)$ & $3(16)$ & $13(43)$ & 0.03 \\
\hline History of cancer & $34(69)$ & $12(63)$ & $22(73)$ & 0.45 \\
\hline Patients with HIV-RNA $<50$ copies $/ \mathrm{ml}$ & $42(86)$ & $15(79)$ & $27(90)$ & 0.29 \\
\hline Mean CD4 cell count (cells/mm³) & $616(246)$ & $649(205)$ & $595(269)$ & 0.45 \\
\hline Mean CD4 nadir (cells/mm³) & $252(195)$ & $251(154)$ & $253(218)$ & 0.97 \\
\hline
\end{tabular}

Table 1: Characteristics of patients at inclusion.

\section{Screening tools results}

Comparison between IHDS, MOCA and FIMF batteries showed the best performances for the latter. In particular, sensitivity, PPV and NPV for the FIMF battery were $87 \%, 72 \%$ and $69 \%$, respectively, while specificity was $47 \%$ (Table 2 ).
As the Five words test and Frontal ability battery did not allow good performance at all, we eliminated them from the screening tool and tried to look at other combinations of tests. The best results were obtained when combining Isaac set test, Memory span test and MOCA, allowing high values of sensitivity, PPV and NPV when performances were below the cut-off for at least one of them (Table 2).

\begin{tabular}{|c|c|c|c|c|c|c|c|c|}
\hline Screening tool (cut-off) & $\begin{array}{l}\text { No HAND } \\
(n=19)\end{array}$ & & $\begin{array}{l}\text { HAND } \\
(n=30)\end{array}$ & & & & & \\
\hline & $\mathbf{n}$ & $\%$ & $\mathbf{n}$ & $\%$ & $\begin{array}{c}\text { Sensitivity } \\
(\%)\end{array}$ & $\begin{array}{c}\text { Specificity } \\
(\%)\end{array}$ & VPP (\%) & VPN (\%) \\
\hline IHDS $(\leq 10)$ & & & & & 70.0 & 47.4 & 67.7 & 50.0 \\
\hline No & 9 & 50.0 & 9 & 50.0 & & & & \\
\hline Yes & 10 & 32.3 & 21 & 67.7 & & & & \\
\hline MOCA $(<26)$ & & & & & 36.7 & 84.2 & 78.6 & 45.7 \\
\hline No & 16 & 45.7 & 19 & 54.3 & & & & \\
\hline Yes & 3 & 21.4 & 11 & 78.6 & & & & \\
\hline Five words test $(<10)$ & & & & & 6.7 & 89.5 & 50.0 & 37.8 \\
\hline No & 17 & 37.8 & 28 & 62.2 & & & & \\
\hline Yes & 2 & 50.0 & 2 & 50.0 & & & & \\
\hline Frontal ability battery $(\leq 15)$ & & & & & 13.3 & 94.7 & 80.0 & 40.9 \\
\hline No & 18 & 40.9 & 26 & 59.1 & & & & \\
\hline Yes & 1 & 20.0 & 4 & 80.0 & & & & \\
\hline ISAAC set test $(\leq 38)$ & & & & & 76.7 & 63.2 & 76.7 & 63.2 \\
\hline No & 12 & 63.2 & 7 & 36.8 & & & & \\
\hline Yes & 7 & 23.3 & 23 & 76.7 & & & & \\
\hline Memory span test $(<5)$ & & & & & 30.0 & 78.9 & 69.2 & 41.7 \\
\hline No & 15 & 41.7 & 21 & 58.3 & & & & \\
\hline Yes & 4 & 30.8 & 9 & 69.2 & & & & \\
\hline $\begin{array}{l}\text { French battery: Five words test }(<10) \text { or Frontal ability battery }(\leq \\
\text { 15) or Isaac set test }(\leq 38) \text { or Memory span test }(<5)\end{array}$ & & & & & 86.7 & 47.4 & 72.2 & 69.2 \\
\hline No & 9 & 69.2 & 4 & 30.8 & & & & \\
\hline
\end{tabular}


Citation: Vassallo M, Barbaud L, Fabre R, Andersen S, Lebrun-Frenay C, et al. (2017) Evaluation of Three Brief Screening Tests for Older Patients with Mild HIV-Associated Neurocognitive Disorders in the CART Era. J Neurol Neurophysiol 8: 421. doi: $10.4172 / 2155-9562.1000421$

Page 5 of 8

\begin{tabular}{|c|c|c|c|c|c|c|c|c|}
\hline Yes & 10 & 27.8 & 26 & 72.2 & & & & \\
\hline Isaac set test $(\leq 38)$ or Memory span test $(<5)$ or MOCA $(<26)$ & & & & & 90.0 & 47.4 & 73.0 & 75.0 \\
\hline Non & 9 & 75.0 & 3 & 25.0 & & & & \\
\hline Yes & 10 & 27.0 & 27 & 73.0 & & & & \\
\hline Isaac set test $(\leq 38)$ and Memory span test $(<5)$ and MOCA $(<26)$ & & & & & 10.0 & 94.7 & 75.0 & 40.0 \\
\hline Non & 18 & 40.0 & 27 & 60.0 & & & & \\
\hline Yes & 1 & 25.0 & 3 & 75.0 & & & & \\
\hline
\end{tabular}

Table 2: Performance of screening tools.

\begin{tabular}{|c|c|c|c|c|c|c|c|c|}
\hline & \multicolumn{2}{|c|}{ No HAND ( $n=19)$} & \multicolumn{2}{|c|}{ HAND $(n=30)$} & \multirow[b]{2}{*}{ Sensitivity (\%) } & \multirow[b]{2}{*}{ Specificity (\%) } & \multirow[b]{2}{*}{ PPV (\%) } & \multirow[b]{2}{*}{ NPV (\%) } \\
\hline & $\mathbf{n}$ & $\%$ & $\mathbf{n}$ & $\%$ & & & & \\
\hline MOCA+Isaac set test+Memory span test $(\leq 76)$ & & & & & 63.3 & 57.9 & 70.4 & 50.0 \\
\hline No & 11 & 50.0 & 11 & 50.0 & & & & \\
\hline Yes & 8 & 29.6 & 19 & & & & & \\
\hline MOCA+Isaac set test+Memory span test $(\leq 77)$ & & & & & 66.7 & 52.6 & 69.0 & 50.0 \\
\hline No & 10 & 50.0 & 10 & 50.0 & & & & \\
\hline Yes & 9 & 31.0 & 20 & 69.0 & & & & \\
\hline MOCA+Isaac set test+Memory span test $(\leq 78)$ & & & & & 80.0 & 52.6 & 72.7 & 62.5 \\
\hline No & 10 & 62.5 & 6 & 37.5 & & & & \\
\hline Yes & 9 & 27.3 & 24 & 72.7 & & & & \\
\hline MOCA+Isaac set test+Memory span test $(\leq 79)$ & & & & & 80.0 & 31.6 & 64.9 & 50.0 \\
\hline No & 6 & 50.0 & 6 & 50.0 & & & & \\
\hline Yes & 13 & 35.1 & 24 & 64.9 & & & & \\
\hline MOCA+Isaac set test+Memory span test $(\leq 80)$ & & & & & 83.3 & 31.6 & 65.8 & 54.5 \\
\hline No & 6 & 54.5 & 5 & 45.5 & & & & \\
\hline Yes & 13 & 34.2 & 25 & 65.8 & & & & \\
\hline
\end{tabular}

Table 3: Combination of tests and cut-off values (Area under the ROC curve: 0,635).

Using Roc curves, the cut-off value of 78 for the combination of these three tests showed the best performances (Table 3 and Figure 1).

\section{Discussion}

In a population of older HIV-infected patients, a high percentage of subjects were diagnosed with mild forms of HAND, the majority of impairment represented by a sub-cortical phenotype, such in younger individuals, but also, in some cases, by learning deficit. These results confirm what has been previously showed in cART experienced elderly HIV-infected subjects, where a mixed cortical-subcortical phenotype of impairment could be detected $[9,41,42]$. No cases of severe depression were found, thus reducing risks for confounding behavioural disorders.

J Neurol Neurophysiol, an open access journal
We compared three different screening tools. Performances of IHDS and MOCA were poor, confirming their limits for detecting HAND in the CART era, where most frequent phenotypes are represented by mild impairments, symptomatic or not.

The FIMF battery showed the best performances, although specificity was poor. The combination of two tests included in this battery (Isaac set test and Memory span test) with MOCA displayed still more interesting results. Although poor specificity requires further more performing tools, these results are encouraging considering that the large majority of impaired patients had the mildest and most difficult to diagnose form of HAND, represented by ANI. A cut-off value of 78 for this combination of tests had been identified for discriminating patients with HAND, but the best performances seem to be joined when considering subjects as impaired simply in case of at least one test below the norms. 
Citation: Vassallo M, Barbaud L, Fabre R, Andersen S, Lebrun-Frenay C, et al. (2017) Evaluation of Three Brief Screening Tests for Older Patients with Mild HIV-Associated Neurocognitive Disorders in the CART Era. J Neurol Neurophysiol 8: 421. doi: $10.4172 / 2155-9562.1000421$

Page 6 of 8

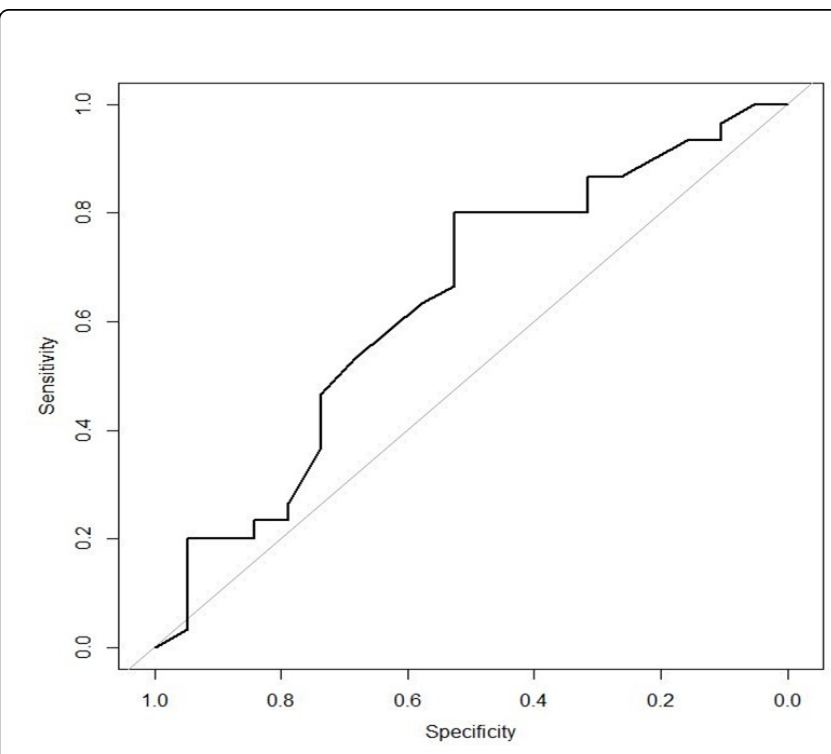

Figure 1: Receiver operating characteristic (ROC) curve combining MOCA, Isaac set test and Memory span test. Unimpaired subjects versus patients with HAND (Area under the curve=0.635).

ANI is the most frequent form of HAND in the cART era. Its role is controversial, as some authors had suggested potential risks of overdiagnosis due to too severe norms of the AAN revised criteria $[43,44]$. Moreover, we recently showed that aviremic patients with ANI do not display the same pattern of immune activation than MND, suggesting that this definition is not stringent and not represent overt disease, or that it is a pre-clinical condition of more severe forms of impairment [34]. However, others have showed that patients with ANI have higher risks to deteriorate over time than unimpaired subjects [45-47]. Therefore, despite the ongoing debates about its real role, diagnosing ANI is one of main priorities and difficulties in the management of HAND in the cART era. Screening tools could be useful for identifying patients needing more accurate NP evaluation in order to confirm diagnosis, especially in settings where availability of neuropsychologists for the clinical routine is scarce.

Our results, although they are more favourable than other screening batteries currently used for detecting HAND, show poorer performances than the recently published CogState-based screening procedure [13]. Indeed, Bloch et al. found excellent results in terms of sensitivity, specificity, PPV and NPV in a population of HIV-infected patients mainly presenting with mild forms of HAND. However, this study is hampered by some methodological bias that limits its definitive validation as the gold standard among screening tools. Indeed, authors did not test the entire population with the large NP battery, but only those having the poorest performances with the CogState screening test, while subjects with ANI or normal tests were not systematically tested by the large battery. This method limits, to us, the real capacity of such screening battery to detect the mildest forms of HAND and risks to overestimate its performances by potentially excluding patients with false normal performances with the screening battery. Moreover, a significant number of subjects included had potential confounding factors such as previous CNS opportunistic infections or a history of non-HIV neurological or psychiatric condition.
Among limits of our study, there are the small number of subjects included, the lack of a control group of HIV-subjects and the absence of a screening test for speed of information processing, which probably would have improved performances of such tools. Indeed, screening tools usually focus only on some neurocognitive domains in order to obtain some easy-to-perform tools, thus potentially limiting their performances. Besides, although difference was not statistically significant, there was an overrepresentation of women in the HAND group compared to the majority of men in the entire population studied. Moreover, although the large majority of subjects included were Caucasians, where clade B viruses are the most prevalent, we did not include in the analysis data about subtypes of HIV, which could potentially alter performances on NP testing. Another limit of the study could be the low number of subjects detected with MND, which is in line with the majority of studies on prevalence of HAND in the cART era. Indeed, the large majority of phenotypes of impairment are at present represented by the ANI group. Therefore, although both ANI and MND reflect mild neurocognitive disorders according to the AAN revised criteria, these subgroups were not equally represented, as a consequence of the study design.

\section{Conclusion}

In conclusion, the combination of MOCA, Isaac set test and Memory span test could be considered as a useful easy-to perform screening tool for identifying mild forms of HAND in the cART era.

\section{Acknowledgement}

We would like to thank Bruno Malafronte, Dominique Hoffer, Sandrine Dipace and Eliane Sfinij who provided helpful work to patients recruiting.

\section{Author's Contributions}

Conceived and designed the study: MV. Performed the study: MV, LB. Analysed data: RB, CP. Wrote the manuscript: MV, BD. Edited the manuscript: SA, NM, CLF, HJ.

\section{Study Funding}

This study received funding from AbbVie Company. AbbVie did not participate in the design or the conduct of the study, in the collection, management, analysis and interpretation of data or in the preparation, review or approval of the manuscript. All the phases of the work described above were prepared independently by the authors.

\section{Conflict of Interest}

The authors have no conflict of interest to declare.

\section{References}

1. Scott JC, Woods SP, Vigil O, Heaton RK, Schweinsburg BC, et al. (2011) A neuropsychological investigation of multitasking in HIV infection: implications for everyday functioning. Neuropsychology 25: 511-519.

2. Larussa D, Lorenzini P, Cingolani A, Bossolasco S, Grisetti S, et al. (2006) Highly active antiretroviral therapy reduces the age-associated risk of dementia in a cohort of older HIV-1-infected patients. AIDS Res Hum Retroviruses 22: 386-392.

3. Valcour V, Shikuma C, Shiramizu B, Watters M, Poff P, et al. (2004) Higher frequency of dementia in older HIV-1 individuals: the Hawaii Aging with HIV-1 Cohort. Neurology 63: 822-827. 
Citation: Vassallo M, Barbaud L, Fabre R, Andersen S, Lebrun-Frenay C, et al. (2017) Evaluation of Three Brief Screening Tests for Older Patients with Mild HIV-Associated Neurocognitive Disorders in the CART Era. J Neurol Neurophysiol 8: 421. doi: $10.4172 / 2155-9562.1000421$

Page 7 of 8

4. Valcour VG, Shikuma CM, Watters MR, Sacktor NC (2004) Cognitive impairment in older HIV-1-seropositive individuals: prevalence and potential mechanisms. AIDS 18: S79-86.

5. Becker JT, Lopez OL, Dew MA, Aizenstein HJ (2004) Prevalence of cognitive disorders differs as a function of age in HIV virus infection. AIDS 1: S11-18.

6. Dauchy FA, Amieva H, Collin C, Bonnet F, Neau D, et al. (2009) Troubles cognitifs chez les personnes infectées par le VIH: prévalence et facteurs associés au sein de la cohorte ANRS CO3 Aquitaine, une analyse intermediaire. Med Mal Infect 39: S1.

7. McArthur JC, Steiner J, Sacktor N, Nath A (2010) Human immunodeficiency virus-associated neurocognitive disorders: Mind the gap. Ann Neurol 67: 699-714.

8. Vassallo M, Dunais B, Durant J, Carsenti-Dellamonica H, HarveyLangton A, et al. (2013) Relevance of lipopolysaccharide levels in HIVassociated neurocognitive impairment: The Neurdapt study. J Neurovir 19: 376-382.

9. Heaton RK, Franklin DR, Ellis RJ, McCutchan JA, Letendre SL, et al. (2011) HIV-associated neurocognitive disorders before and during the era of combination antiretroviral therapy: differences in rates, nature and predictors. J Neurovirol 17: 3-16.

10. Chan P, Brew BJ (2014) HIV associated neurocognitive disorders in the modern antiviral treatment era: Prevalence, characteristics, biomarkers and effects of treatment. Current HIV/AIDS Rep 11: 317-324.

11. Antinori A, Arendt G, Becker JT, Brew BJ, Byrd DA, et al. (2007) Updated research nosology for HIV-associated neurocognitive disorders. Neurology 69: 1789-1799.

12. Skinner S, Adewale AJ, DeBlock L, Gill MJ, Power C (2009) Neurocognitive screening tools in HIV/AIDS: comparative performance among patients exposed to antiretroviral therapy. HIV Med 10: 246-252.

13. Bloch M, Kamminga J, Jayewardene A, Bailey M, Carberry A, et al. (2016) A screening strategy for $\mathrm{HIV}$-associated neurocognitive disorders that accurately identifies patients requiring neurological review. Clin Infect Dis 63: 687-693.

14. Kabuba N, Anitha Menon J, Franklin DR, Heaton RK, Hestad KA (2016) Use of western neuropsychological test battery in detecting HIVassociated neurocognitive disorders (HAND) in Zambia. AIDS Behav.

15. Overton ET, Kauwe JS, Paul R, Tashima K, Tate DF, et al. (2011) Performances on the CogState and standard neuropsychological batteries among HIV patients without dementia. AIDS Behav 15: 1902-1909.

16. Sacktor NC, Wong M, Nakasujja N, Skolasky RL, Selnes OA, et al. (2005) The international HIV dementia scale: A new rapid screening test for HIV dementia. AIDS 19: 1367-1374.

17. Bottiggi KA, Chang JJ, Schmitt FA, Avison MJ, Mootoor Y, et al. (2007) The HIV dementia scale: Predictive power in mild dementia and HAART. J Neurol Sci 260: 11-15.

18. Cysique LA, Murray JM, Dunbar M, Jeyakumar V, Brew BJ (2010) A screening algorithm for HIV-associated neurocognitive disorders. HIV Med 11: 642-649.

19. Fasel D, Kunze U, Elzi L, Werder V, Niepmann S, et al. (2014) A short tool to screen HIV-infected patients for mild neurocognitive disorders - A pilot study. BMC Psychol 2: 21.

20. Janssen MA, Meulenbroek O, Steens SC, Góraj B, Bosch M, et al. (2015) Cognitive functioning, well-being and brain correlates in HIV-1 infected patients on long-term combination antiretroviral therapy. AIDS 29: 2139-2148.

21. Kim WJ, Ku NS, Lee YJ, Ahn JY, Kim SB, et al. (2016) Utility of the Montreal cognitive assessment (MoCA) and its subset in HIV-associated neurocognitive disorder (HAND) screening. J Psychosom Res 80: 53-57.

22. Joska JA, Witten J, Thomas KG, Robertson C, Casson-Crook M, et al. (2016) A comparison of five brief screening tools for HIV-associated neurocognitive disorders in the USA and South Africa. AIDS Behav 20: 1621-1631.

23. Derouesné C, Poitreneau J, Hugonot L, Kalafat M, Dubois B, et al. (1999) Le Mental-State Examination (MMSE): un outil pratique pour lévaluation de létat cognitif des patients par le clinicien. Version française consensuelle. Presse Méd 28: 1141-1148.

24. Van der Linden M, Coyette F, Poitrenaud J, Adam S (2004) The free recall/recall test with 16 items (RL/RI-16). In book: Evaluation of memory disorders: Presentation of four episodic memory tests with their calibration. Marseille: Solal, France.

25. Bayard S, Erkes J, Moroni C (2009) Test of the Victoria stroop - French adaptation: material, instructions, quotation procedure and normative data. College of Psychologists Clinicians specialized in Neuropsychology of Languedoc Roussillon (CPCN-LR).

26. Cardebat D, Doyon B, Puel M, Goulet P, Joanette Y (1990) Formal and semantic lexical evocation in normal subjects. Performance and dynamics of production as a function of sex, age and educational level. Acta Neurologica Belgica 90: 207-217.

27. Agniel A, Doyon B, Joanette Y, Duchein C (2001) Protocole MontréalToulouse: Evaluation des gnosies visuelles et auditives. Isbergues: Ortho Edition.

28. Wechsler D (2011) WAIS-IV. Paris: ECPA.

29. Trites RL (2003) Grooved Pegboard : User's manual. IN:Lafayette Instrument Company

30. Tombaugh TN (2004) Trail Making Test A and B: normative data stratified by age and education. Arch Clin Neuropsychol 19: 203-214.

31. Deloche G, Hannequin D (1997) Test de denomination orale d'image DO80. Paris: ECPA

32. Mahieux-Laurent F, Fabre C, Galbrun E, Dubrulle A, Moroni C, et al. (2009) Validation of a brief screening scale evaluating praxic abilities for use in memory clinics. Evaluation in 419 controls, 127 mild cognitive impairment and 320 demented patients. Rev Neurol (Paris) 165: 560-567.

33. Tozzi V, Balestra P, Lorenzini P, Bellagamba R, Galgani S, et al. (2005) Prevalence and risk factors for $\mathrm{HIV}$-associated neurocognitive impairment, 1996 to 2002: Results from an urban observational cohort. J Neurovirol 11: 265-273.

34. Julayanont P, Tangwongchai S, Hemrungrojn S, Tunvirachaisakul C, Phanthumchinda K, et al. (2015) The Montreal cognitive assessmentbasic: A screening tool for mild cognitive impairment in illiterate and low-educated elderly adults. J Am Geriatr Soc 63: 2550-2554.

35. Yeni P (2010) Report: The medical care of people infected with HIV.

36. Dubois B, Slachevsky A, Litvan I, Pillon B (2000) The FAB: A frontal assessment battery at bedside. Neurology 55: 1621-1626.

37. Antérion CT, Honoré S, Cougny H, Grosmaitre C, Laurent B (2001) Contribution of lexical recall in the set test in Alzheimer disease screening. Rev Neurol (Paris) 157: 1377-1382.

38. Gass CS, Gutierrez L (2016) Psychological variables and Wechsler Adult Intelligence Scale-IV performance. Appl Neuropsychol Adult .

39. Tulving E, Thomson D (1973) Encoding specificity and retrieval processes in episodic memory. Psychol Rev 80: 352-373

40. Cowppli-Bony P, Fabrigoule C, Letenneur L, Ritchie K, Alpérovitch A, et al. (2005) Validity of the five-word screening test for Alzheimer's disease in a population based study. Rev Neurol (Paris) 161: 1205-1212.

41. Sacktor N, Skolasky RL, Seaberg E, Munro C, Becker JT, et al. (2016) Prevalence of HIV-associated neurocognitive disorders in the multicenter AIDS cohort study. Neurology 86: 334-340.

42. Sacktor N, Robertson K (2014) Evolving clinical phenotypes in HIVassociated neurocognitive disorders. Curr Opin HIV AIDS 9: 517-520.

43. Gisslen M, Price RW, Nilsson S (2011) The definition of HIV-associated neurocognitive disorders: Are we overestimating the real prevalence? BMC Infect Dis 11: 356.

44. Torti C, Focà E, Cesana BM, Lescure FX (2011) Asymptomatic neurocognitive disorders in patients infected by HIV: fact or fiction? BMC Med 9: 138.

45. Vassallo M, Durant J, Lebrun-Frenay C, Fabre R, Ticchioni M, et al. (2015) Virologically suppressed patients with asymptomatic and symptomatic HIV-associated neurocognitive disorders do not display the same pattern of immune activation. HIV Med 16: 431-440. 
Citation: Vassallo M, Barbaud L, Fabre R, Andersen S, Lebrun-Frenay C, et al. (2017) Evaluation of Three Brief Screening Tests for Older Patients with Mild HIV-Associated Neurocognitive Disorders in the CART Era. J Neurol Neurophysiol 8: 421. doi: $10.4172 / 2155-9562.1000421$

Page 8 of 8

46. Grant I, Franklin DR, Deutsch R, Woods SP, Vaida F, et al. (2014) Asymptomatic HIV-associated neurocognitive impairment increases risk for symptomatic decline. Neurology 82: 2055-2062.
47. Heaton RK, Franklin DR, Deutsch R, Letendre S, Ellis RJ, et al. (2015) Neurocognitive change in the era of HIV combination antiretroviral therapy: The longitudinal CHARTER study. Clin Infect Dis 60: 473-480. 